\title{
Tecendo ideias para a reutilização de tecidos
}

\author{
Heliana Marcia Santos; \\ Maria Concebida Pereira; \\ Bruno Montanari Razza
}

\section{resumo:}

\begin{abstract}
A inovação social busca a transformação e o melhoramento da qualidade de vida a partir de soluções para os problemas da sociedade $O$ objetivo deste artigo é, portanto, relacionar através de um relato de experiencia do projeto de extensão Programa Institucional de Capacitação de Mulheres em Situação de Vulnerabilidade Social - IFMulher do Instituto Federal do Sul de Minas, nesse sentido surge o importante papel das instituições de ensino na promoção de inovações sociais destacando o projeto desenvolvido para o curso de Formação Inicial e Continuada (FIC), com objetivo capacitar mulheres em situação de vulnerabilidade social, cadastradas na Secretaria Municipal de Assistência Social de Passos - MG, na produção de bolsas artesanais de resíduos têxteis (retalhos de tecidos) da indústria de confecção do vestuário.
\end{abstract}

\section{palavras-chave:}

Projeto de extensão; design de moda; resíduos têxteis; capacitação, inovação social 


\section{Introdução}

A inserção de mulheres no mercado de trabalho consiste em um grande problema social que acomete todo território Nacional e esse quadro é mais agravado quando se trata de famílias de baixa renda ou situação de vulnerabilidade social. Esse é um dos fatores que contribui para um despreparo profissional, pois muitas vezes essas mulheres não frequentaram a escola devido a necessidade de trabalharam desde de muito cedo em ocupações que não exigiam maior qualificação profissional. Esse cenário é mais agravado se considerar que boa parte dessas mulheres são as únicas responsáveis pelo sustento da família (GOMES; PEREIRA, 2005).

Umas das formas de minimizar essa distância entre mulheres em situação de vulnerabilidade social e o mercado de trabalho é qualifica-las para que tenham instrumentos e habilidades que possibilitem diferenciá-las no mercado. Isso reforça a ideia de que o aprendizado pode proporcionar qualificação profissional e bem-estar social para suprir as necessidades e melhorar a qualidade de vida destas mulheres vulneráveis (BARBOSA, 2018).

As ações voltadas para a capacitação devem possibilitar o desenvolvimento de competências articuladas às demandas reais do mercado de trabalho. Essas ações devem visar a concepção do trabalho como um princípio educativo, articulando o conhecimento intelectual à prática (o fazer), rompendo a separação entre o trabalho manual e o trabalho intelectual. Assim, é importante considerar que as práticas de qualificação sejam diretamente aplicáveis em situações reais de trabalho (BIGNETTI, 2011; FREIRE, 2008).

Um dos papéis do design é de propor soluções por meio de produtos para os problemas sociais e econômicos da sociedade, utilizando de tecnologias e criatividade para gerar melhorias no processo produtivo e nos impactos ambientais. Propostas de produtos que utilizem essa matéria-prima devem ser encorajadas. O papel do design, neste caso, é de desenvolver produtos e trabalhar com a capacitação de indivíduos, promovendo a integração social e valorização do indivíduo. Estas iniciativas estão de acordo com políticas de desenvolvimento socioambiental, e podem ser beneficiárias de investimentos públicos ou facilidades de financiamento (SANTOS, 2015).

Neste contexto, é importante considerar as instituições de Ensino Superior, especialmente as Instituições Públicas, como um agente agregador de conhecimentos, especialmente aqueles voltados para a formação de profissionais, podendo atuar no sentido de diminuir a distância dessa população ao ensino superior e ao mercado de trabalho. As atividades de capacitação são uma das formas mais sensíveis de aproximar as instituições de ensino a essa população vulnerável, aumentando suas chances de aprendizados profissional e de futura inserção no mercado de trabalho (FREIRE, 2008).

Por isso é imprescindível aliar a capacidade técnica institucional e sua área de atuação para reduzir as distancias entre a universidade e a comunidade, portanto é necessário um planejamento consciente de como transferir conhecimento específicos que possam ser utilizados de forma prática e direta a essas mulheres. Um dos caminhos é aproveitar a área de intersecção existente entre o conhecimento acadêmico e o sistema produtivo local, atuando neste grupo de para facilitar seu ingresso no mercado de trabalho (FREIRE, 2008).

O objetivo deste artigo é, portanto, relacionar através de um relato de experiencia do projeto de extensão Programa Institucional de Capacitação de Mulheres em Situação de Vulnerabilidade Social - IFMulher do Instituto Federal do Sul de Minas - Campus Passos, buscando a melhoria das condições de vida e fomentar bolsas de auxílio para as mulheres que estejam, comprovadamente, em situação de vulnerabilidade econômica e que fizerem os cursos aprovados neste edital e o papel do design como um dos agentes responsáveis para o desenvolvimento de novos produtos inseridos na capacitação de mulheres vulneráveis e de apresentar uma proposta de produto com novo material, neste caso os resíduos têxteis como uma prática de inovação social.

\section{Referencial Teórico}

O descarte da indústria de confecção é uma matéria-prima com grande potencial de utilização, pois se encontra em estado original (sem degradação e quase sempre sem mistura com outros resíduos) e está disponível em grande quantidade, mas na forma de retalhos que são pequenos pedaços de tecido em formado desigual (SANTOS, 2015). 
O conceito de trabalho que fundamenta a produção estatística no Brasil é caracterizado pela ideia de produção e mercantilização. Segundo Censo 2010 (IBGE, 2012) considera como dados, trabalhos como atividade econômica, atividades com ocupação remunerada, atividades domésticas não são consideradas trabalho. Segundo Azevedo (2012), o conceito de atividade é excludente e desconsidera o trabalho não remunerado desenvolvido no espaço doméstico de cuidado do próprio domicílio, de filhos, idosos, doentes, como uma atividade que contribui para a produção e reprodução da vida e que gera valor. Exclui-se, portanto, já de imediato, pouco menos de metade das mulheres que, por razões diversas, mas especialmente por conta das responsabilidades domésticas, não conseguem lançar-se ao mercado de trabalho.

O mercado de produção artesanal tem crescido muito atualmente em termos mundiais, e o mercado nacional tem acompanhado esse desenvolvimento. Os principais avanços no setor estão relacionados diretamente ao design dos acessórios que incorporam materiais alternativos ou faz-se uso de uma técnica tradicional e adapta a outro tipo de material, como por exemplo os resíduos têxteis das indústrias de confecções. Este mercado tem se direcionado para produtos de design diferenciado e de alta qualidade de acabamento, mas que não utilize materiais nobres e sim apresentam uma característica formal que o destaque (AZEVEDO, 2012).

As indústrias criativas compreendem os processos de criação, produção e distribuição de bens e serviços que utilizam a criatividade e capital intelectual como bens primários. Elas constituem atividades baseadas no conhecimento, cultura e arte, como gerador de receitas e desenvolvimento humano.

O termo economia criativa foi cunhado por Howkins (2012), como um novo modelo de investimento e desenvolvimento econômico mais viável frente às transformações sociais e culturais recentes, como a globalização, as novas mídias digitais, a falência dos modelos econômicos tradicionais em promover desenvolvimento, a inclusão e a valorização. O BNDES inclui em sua pauta de investimento e financiamento o Design Estratégico como um agente transformador da sociedade e de desenvolvimento tecnológico cultural. Este projeto está inserido neste contexto.

Manzini (2014:67) afirma que o design pode "considerar sua criatividade e cultura como ferramenta", portanto o designer não somente facilita o processo com o uso de ferramentas tampouco atua de modo que possa interferir demais no processo, ele usa sua criatividade, seu conhecimento em design, e sua capacidade dialógica para "fazer as coisas acontecerem" no processo de Design para a Inovação Social.

A cidade de Passos (MG) é conhecida como referência de produção da indústria de confecção, absorvendo grande quantidade de mão de obra especializada neste setor. Considerando a quantidade de empresas de confecção de moda, podendo estas empresas fornecer material básico para as confecções dos acessórios em cestaria.

O IFSULDEMINAS, por meio do curso de Design de Moda, localizado no Campus de Passos, tem desenvolvido trabalhos relacionados ao uso dos descartes têxteis (retalhos), evidenciando uma vocação local para o desenvolvimento de produtos que vem de encontro ao crescimento do mercado local. Essas atividades estão relacionadas a pesquisas e desenvolvimento de produtos, para o desenvolvimento de mulheres em situação de vulnerabilidade social que possam desenvolver um produto e até mesmo uma marca, produzir seus modelos e vendê-los.

\section{Metodologia}

A Reitoria do Instituto Federal de Educação, Ciência e Tecnologia do Sul de Minas Gerais, em parceria com a Pró-Reitoria de Extensão, divulgou um Edital No 89/2017 de chamada para seleção de Projetos para integrarem o Programa Institucional de Capacitação de Mulheres em Situação de Vulnerabilidade Social - IFMulher.

O objetivo desde Edital $N^{o}$ 89/2017 foi fomentar cursos de capacitação para mulheres em situação de vulnerabilidade social das regiões onde o IFSULDEMINAS atuou buscando a melhoria das condições de vida delas e de suas famílias, ofertando bolsas de auxílio para as mulheres que estejam, comprovadamente, em situação de vulnerabilidade econômica e contribuir para as políticas de gênero, de equidade, de inclusão e de ações afirmativas, em favor da diminuição dos problemas sociais 
e da erradicação da pobreza. Foram selecionados seis projetos e o Projeto Tear: tecendo ideias para a reutilização das sobras de tecidos foi um dos selecionados.

As atividades de extensão devem promover a transformação social no entorno dos câmpus do IFSULDEMINAS, envolvendo servidores e discentes por meio de programas, projetos, cursos, eventos ou produtos. Proporcionando ações que pode gerar mais impacto por meio das atividades de ensino, pesquisa e extensão e, assim, estimular o desenvolvimento de projetos que equilibrem a geração de desenvolvimento econômico e socioambiental.

O projeto desenvolveu um curso de Formação Inicial e Continuada (FIC), com objetivo capacitar mulheres em situação de vulnerabilidade social, cadastradas na Secretaria Municipal de Assistência Social de Passos - MG, na produção de bolsas artesanais de resíduos têxteis (retalhos de tecidos) da indústria de confecção do vestuário.

\subsection{Público alvo}

O critério de inclusão do público alvo para participar no curso foi: mulheres em vulnerabilidade social, cadastradas na Secretaria Municipal de Assistência Social de Passos-MG; pertencer ao município de Passos; ter idade mínima de 16 anos; escolaridade mínima fundamental incompleto e preencher a ficha de inscrição no IFSULDEMINAS - Campus Passos.

O curso foi ofertado a todas os interessados, havendo divulgação e apresentação prévia no site IFSULDEMINAS - Campus Passos para toda a comunidade. Foram ofertadas quinze (15) vagas, com duração de três (3) meses, carga horária total sessenta (60) horas, a periocidade das aulas eram as terças e quintas feiras com duração total de seis (6) horas semanais, cada aluna receberia um auxílio de trezentos reais, esta quantia foi distribuída por 100 reais mensais para cada aluna bolsista durante a realização do curso.

O curso foi realizado no período de 31 de julho a 04 de outubro de 2018, as aulas eram presenciais e foram todas ministradas no IFSULDEMINAS - Campus Passos. Para realização do curso foi em uma sala destinada para essa finalidade, contendo mesas individuais com cadeiras e todos os materiais e ferramentas foram disponibilizados pelo projeto para a elaboração das técnicas e produção das bolsas foram entregues às alunas.

\subsection{Materiais}

A cidade de Passos (MG) é conhecida como referência de produção da indústria confecção, absorvendo grande quantidade de mão de obra especializada neste setor. Considerando a quantidade de empresas de confecção de moda, podendo estas empresas fornecer material básico para as confecções dos acessórios em cestaria.

Os retalhos para confecção das bolsas, foram doados pela Associação Empório Recriart que é composta por um grupo de artesãs parceiras/desenvolvedoras do projeto de pesquisa e extensão do IFSULDEMINAS intitulado "Resíduos têxteis: desenvolvimento científico e social". O referido projeto tem por objetivo desenvolver metodologia de gestão sustentável para a destinação adequada dos resíduos têxteis vindos do processo produtivo da indústria de confecção do vestuário da cidade de Passos - MG, visando promover o desenvolvimento regional por meio da geração de trabalho e renda. Trata-se de um projeto piloto que propõe um plano de gerenciamento sustentável de resíduos para micro e pequenas empresas de confecção do vestuário, formando uma rede de parceiros públicos e privados, entre eles, uma empresa de confecção local, a Prefeitura Municipal, a ONG Deus Proverá, uma associação de catadores de recicláveis, uma empresa de reciclagem têxtil localizada em Suzano SP. Conta ainda com a colaboração voluntária dos alunos do Curso Superior de Tecnologia em Design de Moda do IFSULDEMINAS - Campus Passos.

\subsection{Estruturação Metodológica do Curso FIC}

A metodologia aplicada no Programa Institucional de Capacitação de Mulheres em Situação de Vulnerabilidade Social - IFMulher busca valorizar a mulher acima de tudo. O curso de Formação Inicial e Continuada (FIC) do Projeto Tear: tecendo ideias para a reutilização das sobras de 
tecidos, a modalidade foi presencial, sendo estruturado em módulo único, totalizando $60 \mathrm{~h} / \mathrm{a}$ de duração, sendo realizado em 10 semanas, com 2 encontros semanais, nas terças e quintas, com duração de $3 \mathrm{~h}$. A equipe foi formada por uma professora do Curso Superior de Tecnologia em Design de Moda do Instituto Federal do Sul de Minas - Campus Passos.

Para isso, diversas etapas de planejamento foram necessárias, considerando a preparação dos materiais, a sequência metodológica dos estudos de técnicas, ferramentas e a capacitação para a construção das bolsas. Os objetivos esperados na realização do Curso FIC Projeto Tear: tecendo ideias para a reutilização das sobras de tecidos foram, que as alunas tivessem conhecimento da técnica de tecimento em tear de prego, usado para confecção de bolsas em palha (Figura 1) e aprender essa mesma técnica utilizando o resíduos têxteis, contribuir assim, com a preservação do meio ambiente, e dando um novo destino aos de resíduos têxteis, que na maioria estão destinados ao aterro do município. Enfim, capacitá-las para uma nova geração de renda familiar.

Figura 1: Sacola de Palha
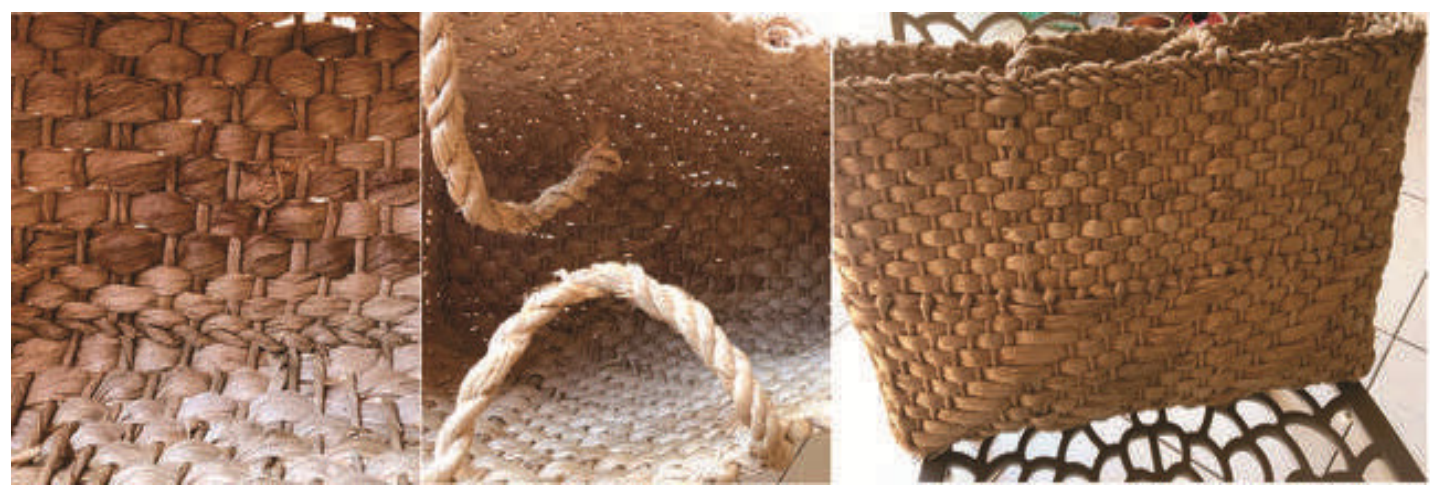

Fonte: Autora

A estrutura metodológica do curso consistiu em conhecer e aplicar a técnica de tecimento em tear de prego na confecção de bolsas artesanais de retalhos (sobras) de tecidos da indústria de confecção do vestuário no processo de aprender fazendo, ou seja, as aulas foram expositivas associadas a práticas aplicadas na elaboração da bolsa (Figura 2). A estrutura metodológica realizada está detalhada no quadro 1.

Quadro 1:.

A primeira fase do curso consistiu no planejamento e preparação do estudo do produto. Foi necessário iniciar alguns estudos de técnicas de tecimento aplicada na construção das bolsas, para que fosse adequado ao processo de aprendizado e desenvolvimento do produto, nesta fase as alunas aprenderam e praticaram a trançar com tiras de papel color set, para ir compreendendo as técnicas de tecimentos e as misturas de cores (figura 2).

Na segunda fase Planejamento da construção da bolsa e a Separação dos retalhos para o tecimento das bolsas nesta fase as alunas construíram a ideia de como seria as cores de suas bolsas. Esses retalhos serão os mesmo que foram descartados da indústria de confecção (figura 3).

Na terceira fase Preparação da corda sisal ou fio rami para passar o urdume no tear; as alunas passaram a corda de sisal ou fio rami, conforme foi definido a construção de sua bolsa na segunda fase de Planejamento da construção da bolsa (figura 4).

Na quarta fase Construção das bolsas, aplicação da técnica de tecimento aprendida na primeira fase (Figura 5).

Na quinta fase as alunas repetirão o mesmo processo da segunda fase, construindo bolsas de 
tamanho diferente, repetindo as técnicas e preparações das fases anteriores (figura 6).

Fonte: Autora.

Figura 2: Primeira Fase.
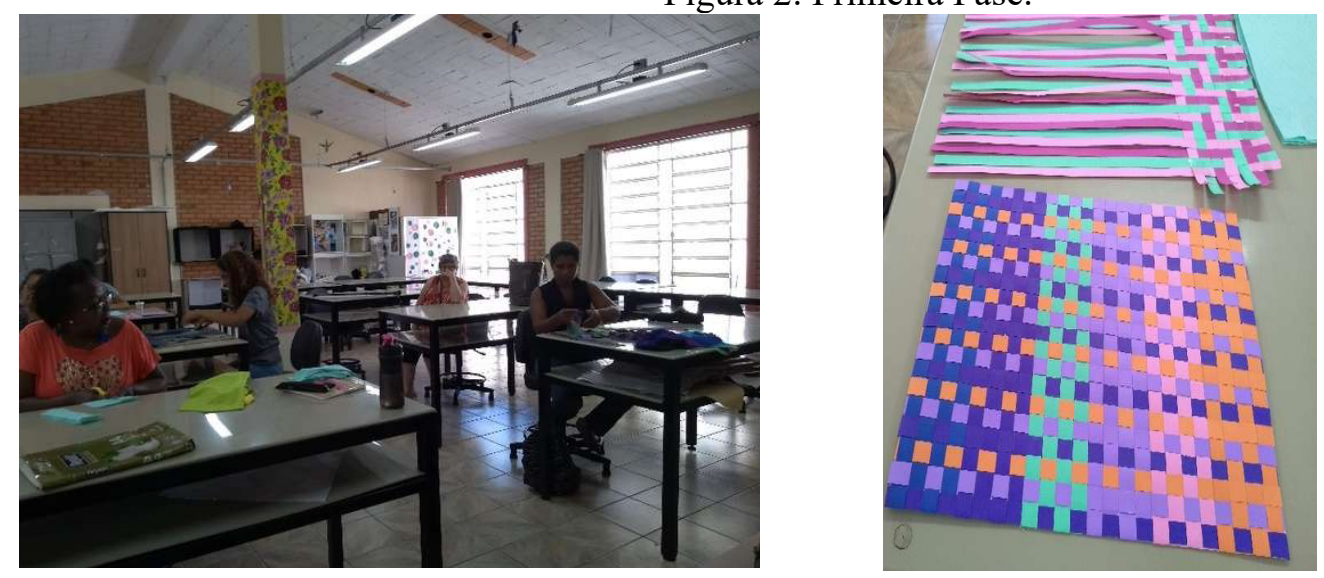

Fonte: Autora.

Figura 3: Segunda Fase.

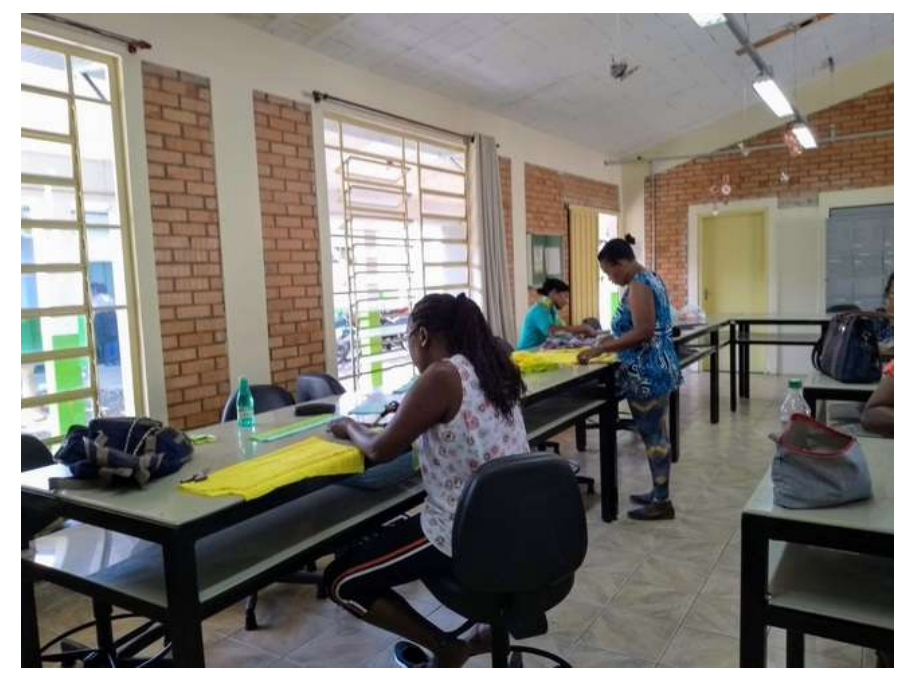

Fonte: Autora.

Figura 4: Terceira Fase. 


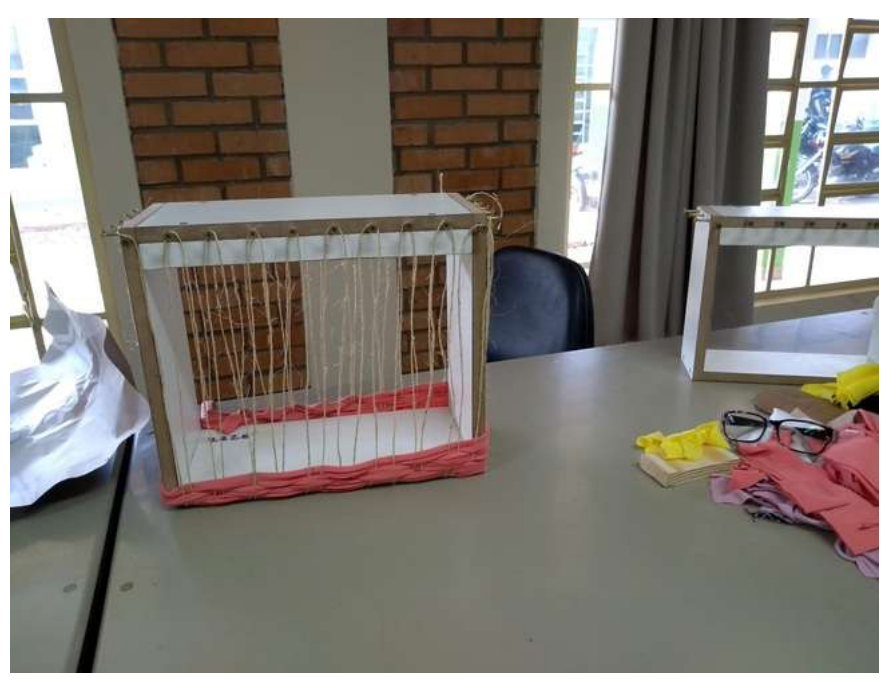

Fonte: Autora.

Figura 5: Quarta Fase.
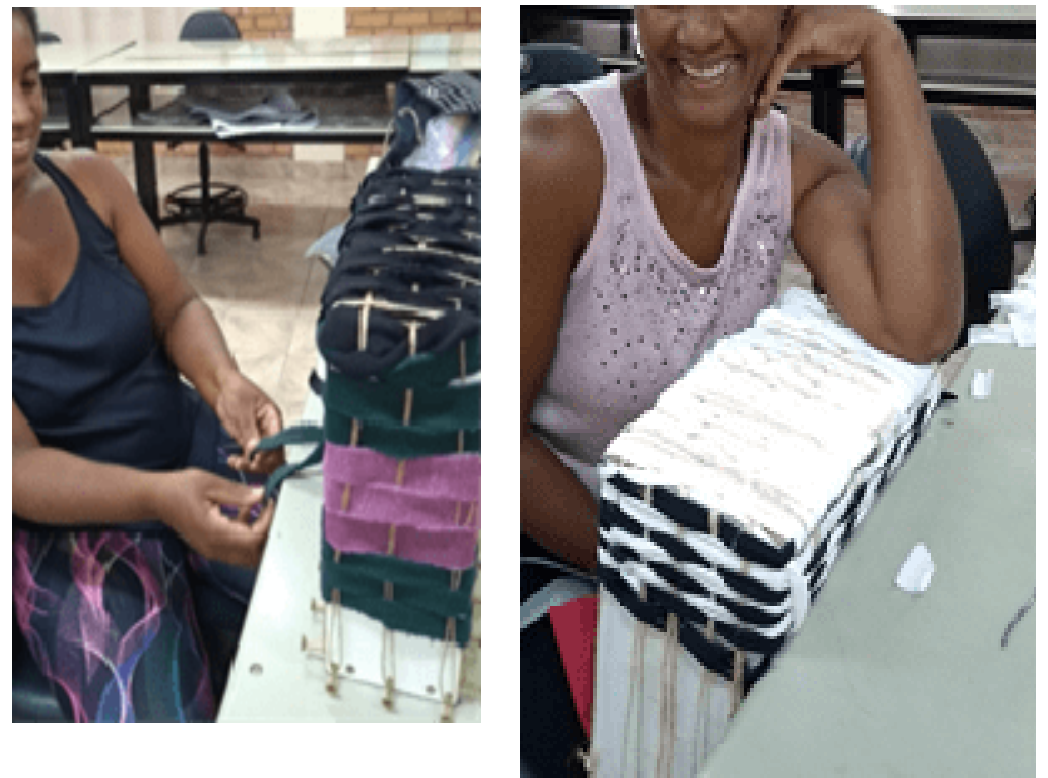

Fonte: Autora.

Figura 6: Quinta Fase. 

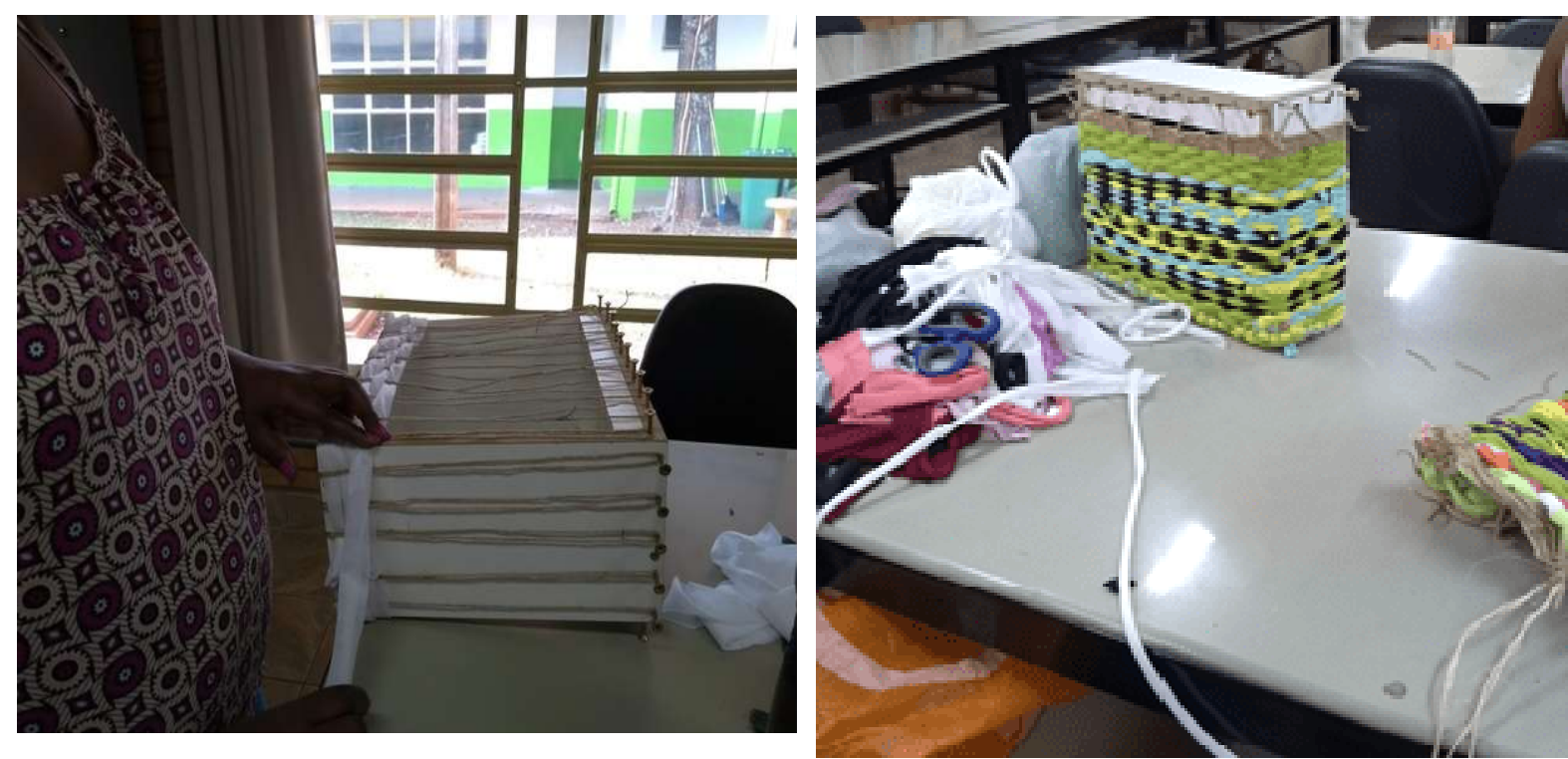

Fonte: Autora.

A sequência metodológica priorizou o avanço gradual de complexidade com a técnica de produção. Esse processo metodológico é baseado em Manzini (2014)), recomenda que a inovação social, não diretamente, mas sim através da articulação de sua rede de atores sobre o que fazer e como fazer. Na Figura 7 é possível observar finalização dos processos de estudo e como ficou a primeira produção das alunas.

Figura 7: Bolsa finalizada.

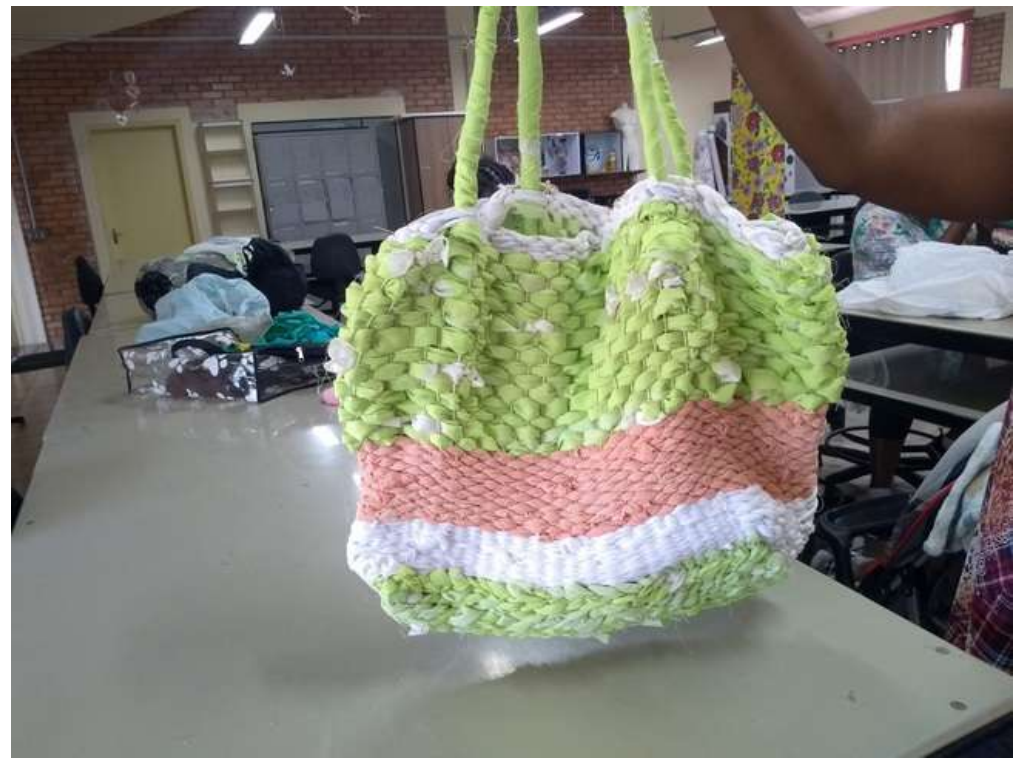

Fonte: Autora. 


\section{Resultados e discussão}

O Curso de Formação Inicial e Continuada (FIC), teve como propósito capacitar mulheres em situação de vulnerabilidade social para o desenvolvimento e produção de bolsas de resíduos têxteis. As matérias-primas principais para a confecção das bolsas, foram de baixos custos pois, utilizaram os retalhos (resíduos têxteis) doados pela Associação Empório Recriart.

A experiência realizada por este projeto foi bastante interessante e enriquecedora, configurando-se uma importante forma de aproximação do IFSULDEMINAS com a comunidade local e também contribuiu com desenvolvimento e inovação do design com as práticas de transformação social e poder proporcionar uma alternativa de geração de renda a partir da confecção de bolsas

A princípio foram ofertadas quinze (15) vagas para alunas extensionistas bolsistas, porém o curso foi realizado com quatro (4) alunas extensionistas bolsistas e quatro (4) alunas extensionistas voluntárias, totalizando oito alunas. O perfil das alunas extensionistas bolsistas eram mulheres do arranjo doméstico monoparental feminino, que são automaticamente definidas como chefe da família devido à ausência do marido ou companheiro e é tipo de família que sempre esteve mais associado ao fenômeno da feminização da pobreza (BARROS; FOX; MENDONÇA, 1994). As alunas tinham cursado o ensino fundamental, no período da manhã trabalhavam fazendo faxinas em outras casas, conforme relatos. O não preenchimento total das vagas foi devido ao horário que o curso estava sendo realizado e muitas outras mulheres que não fizeram o curso porque elas estavam trabalhando nos períodos da manhã e tarde.

O perfil das alunas extensionistas voluntárias eram mais diversificados, uma aluna era casada e dona de casa, duas eram viúvas aposentadas da área de saúde (técnicas de enfermagem) e outra aluna iniciou o curso e posteriormente teve que abandonar por motivo de saúde.

Durante o curso, percebeu-se o quanto participar do grupo contribuiu para o desenvolvimento da autoestima das participantes, foi evidente que muitas das participantes buscam no grupo uma sensação de pertencimento e frequentam as atividades devido aos laços que se formaram.

$\mathrm{O}$ resultado que mais se destacou no curso foi uma aluna que produziu o tear com sobras de madeira em sua casa (figura 8) e iniciou uma pequena produção de bolsas, conforme a figura 4. A aluna teve uma produção maior ora por ter adquirido mais agilidade e também teve um incentivo financeiro, pois, a filha ( figura 9) desta aluna iniciou a produção de venda de bolsas na escola que ela frequentava.

Figura 8: Tear com sobras de madeira.
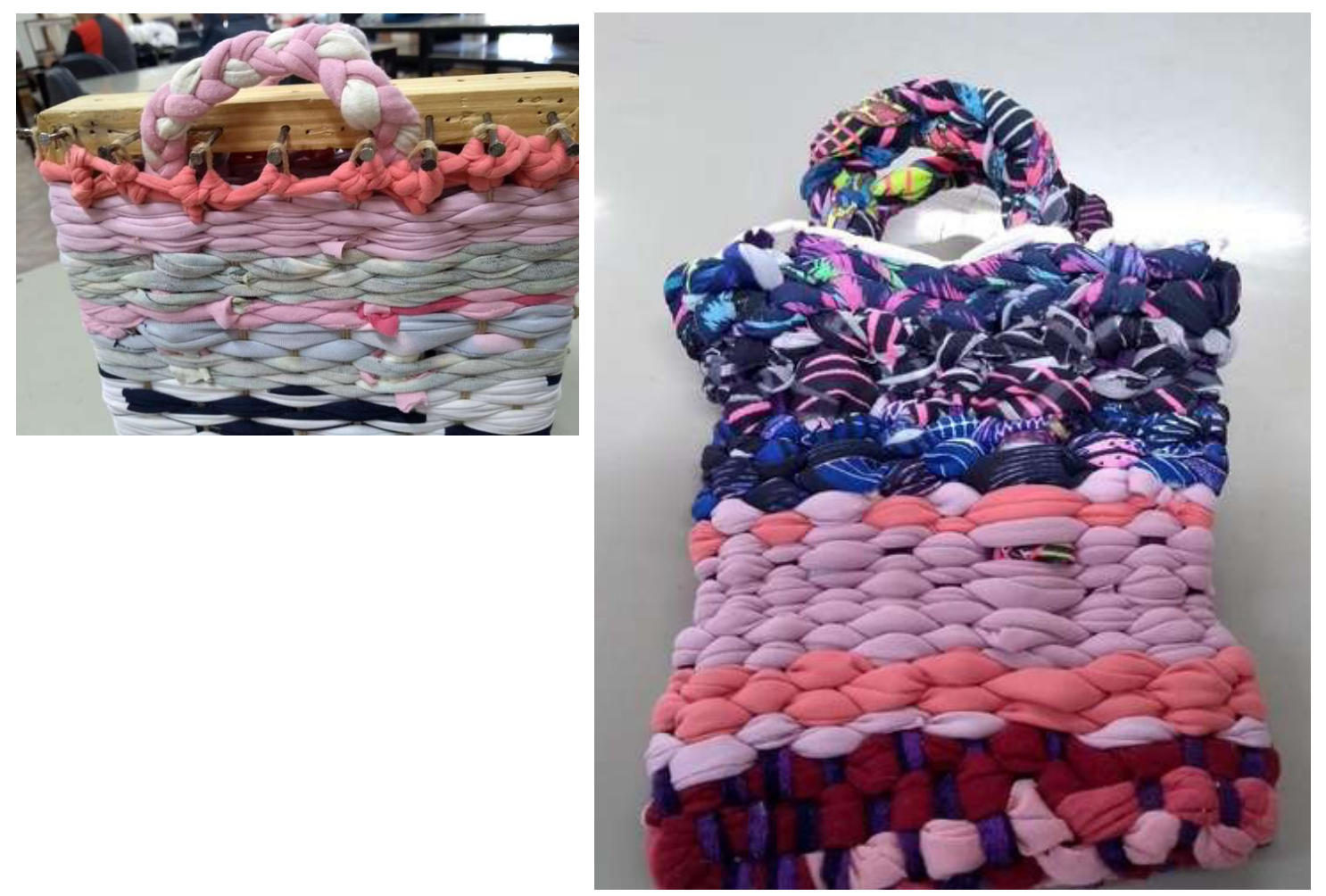


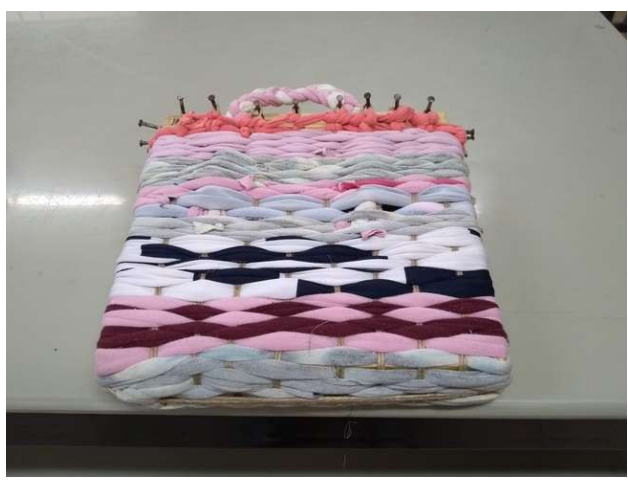

Fonte: Autora

Originalmente, o curso teve um planejamento para a execução mínima de três (3) bolsas para cada aluna, sendo obtido um resultado final de produção duas (2) bolsas por cada aluna (figura 9).

Figura 9: Resultado final das bolsas confeccionadas.

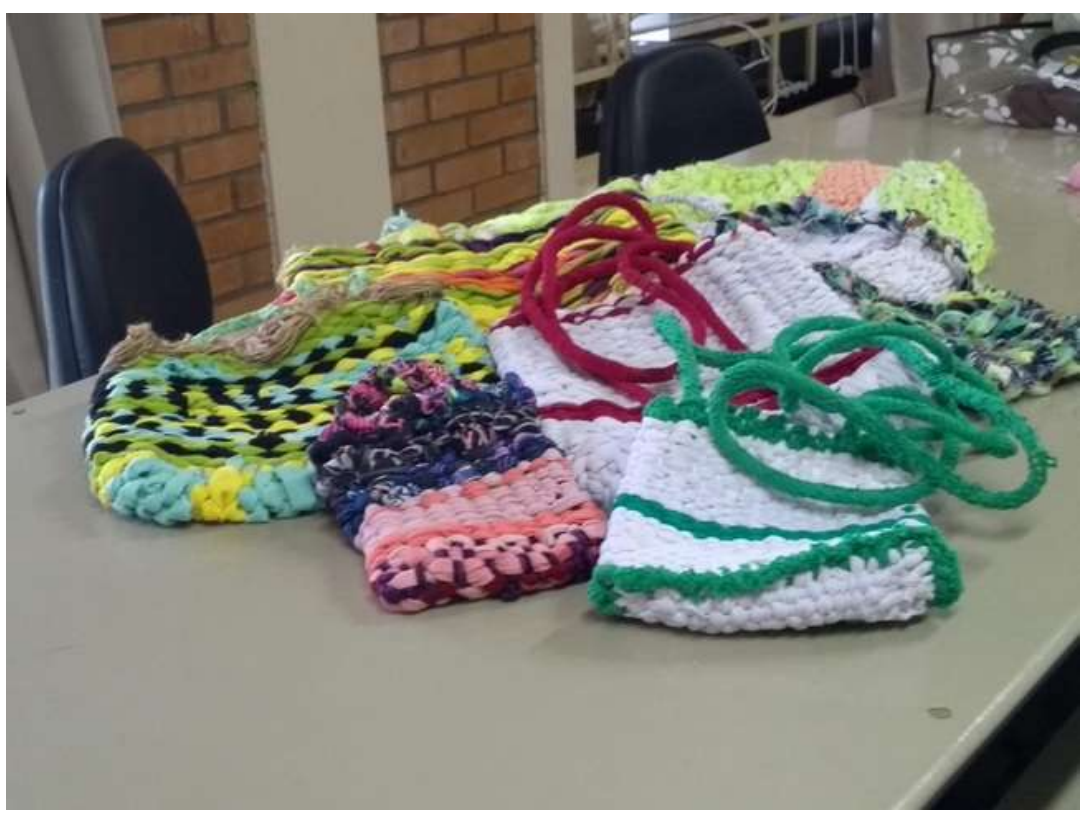

Fonte: Autora

Fato de termos produzidos menos que esperado é que durante o curso percebeu-se que o processo de execução do feitio da bolsa eram mais demorados, que fazer durante as aulas eram muito pouco, as alunas até quiseram que o curso perpetuasse até dezembro de 2018, porém a professora, não tinha mais disponibilidade de tempo para dar continuidade e projeto tinha um cronograma a ser respeitada conforme tabela 2 .

Tabela: 2 Cronograma de execução.

\begin{tabular}{|c|c|c|c|c|}
\hline \multirow[t]{2}{*}{ ATIVIDADES } & \multicolumn{4}{|c|}{ Meses } \\
\hline & Jul & Ago & Set & Out \\
\hline Planejamento e preparação do estudo do produto & $\bar{X}$ & & & \\
\hline Estudos de técnicas de tecimentos & & $\mathrm{X}$ & & \\
\hline Planejamento da construção da bolsa & & $\mathrm{X}$ & & \\
\hline Separação dos retalhos para o tecimento das bolsas & & $\mathrm{X}$ & & \\
\hline
\end{tabular}




\begin{tabular}{|c|c|c|c|}
\hline Preparação da corda sisal ou fio rami para passar o urdume no tear & $\mathrm{X}$ & & \\
\hline Construção da primeira bolsa & $\mathrm{X}$ & $\mathrm{X}$ & \\
\hline Construção da segunda bolsa & & $\mathrm{X}$ & $\mathrm{X}$ \\
\hline
\end{tabular}

Fonte: Autora.

\section{Considerações finais}

A formação de novas relações sociais e novas estruturações sociais é percebida mais fortemente com a aproximação e vínculos com movimentos solidários, como uma alternativa de renda às mulheres por meio da produção de artesanatos, alimentos, etc. A socialização com outras mulheres e a necessidade de contatos contribui com novas relações sociais (BIGNETTI, 2011).

Nesse sentido, a pretensão é relatar a experiência extensionista e contribuir para a construção de um olhar diferenciado aos cursos de capacitação e de extensão universitária. Percebe-se que a política de extensão universitária, assim como o ensino e a pesquisa, tem papel fundamental na garantia de direitos humanos e da cidadania. Embora não configure diretamente como uma política social, a política de extensão na universidade é o passaporte para a efetivação e ampliação da cidadania; para o estreitamento da relação universidade-comunidade externa e para a interlocução de saberes.

A capacitação ocorreu não só com as alunas, como também com a professora, que foi proporcionada pela troca de experiências entre as alunas e o conteúdo que o curso de capacitação proporcionou. Essas consequências impactam na vida em família e na comunidade, modificando as relações sociais e como decorrência modifica a percepção dessas mulheres em relação a elas mesmas e ao meio em que elas vivem, e objetivo de um curso de capacitação também é proporcionar a essas mulheres a inclusão, a melhora da autoestima, a autonomia, além da mudança de perspectivas, ou seja, proporcionando assim melhoras na qualidade de vida.

Em relação ao objetivo do projeto, que é contribuir para a geração de trabalho e renda destas mulheres, acredita-se ser este um objetivo atendido parcialmente, dadas as dificuldades de demandar muito tempo para produção das bolsas. Mesmo assim, as ações desenvolvidas atingiram os resultados proposto e esperado no curso de capacitação do projeto.

Por fim, este artigo limitou-se ao caso do projeto de extensão Programa Institucional de Capacitação de Mulheres em Situação de Vulnerabilidade Social - IFMulher. Embora alinhado com a literatura existente, o estudo representa um caso específico. Assim, sugerem-se novas pesquisas sobre os projetos de extensão em outros agentes da inovação social como, por exemplo, organizações, movimentos sociais sejam ampliados.

Agradecimento: IFSULDEMINAS, Edital No 89/2017.

\section{Weaving ideas for the reuse of fabrics}

Abstract: Social innovation seeks to transform and improve the quality of life based on solutions to society's problems. The goal of this article is, therefore, to report an experience of the university outreach project Institutional Training Program for Women in Social Vulnerability - IFMulher from the Federal Institute of the South of Minas, in this sense the important role of educational institutions in promoting social innovations emerges, highlighting the project developed for the Initial and Continuing Education (FIC) course, aiming to train women in social vulnerability, registered with the Municipal Secretariat of Social Assistance of Passos - MG, in the production of handmade bags of textile residues (scraps of fabrics) from the clothing industry. 


\section{Referências bibliográficas}

AZEVEDO, Lucyana Xavier de. O design e as políticas de apoio ao artesanato: um estudo de caso sobre a relação de patrocínio do grupo Teares Alegria pela Caixa Econômica Federal. Recife, 2012. 117 f. Dissertação (mestrado) - UFPE, Centro de Artes e Comunicação, Programa de Pós-graduação em Design, 2012. Disponível em< https://repositorio.ufpe.br/handle/123456789/11476 > Acesso em 15 jul 2020.

BARBOSA, M. G. Educação, vida precária e capacitação. Revista Educação e Sociedade, v. 39, no. 144, p.584-599, jul.-set., 2018. Disponível em; < https://www.scielo.br/pdf/es/v39n144/1678-4626es-es0101-73302018181445.pdf> acesso em 03 de jun 2020.

BARROS, Ricardo; FOX, Louise; MENDONÇA, Rosane. Pobreza e domicílios chefiados por mulheres. In: SEMINÁRIO NACIONAL POLÍtTCAS ECONÔMICAS, POBREZA E TRABALHO, 2. Rio de Janeiro: IPEA, 1994, p.79-85.

BIGNETTI, Luiz Paulo. As inovações sociais: uma incursão por ideias, tendências e focos de pesquisa. Ciências Sociais Unisinos, v. 47, n. 1, p. 3-14, 2011. Disponível em: <

http://revistas.unisinos.br/index.php/ciencias_sociais/article/view/1040 > acesso em 03 de jun 2020.

CASTRO, Luciana Maria Cerqueira. A universidade, a extensão universitária e a produção de conhecimentos emancipadores. In: REUNIÃO ANUAL DA ANPED, 27. Caxambu, 2004.Disponível em; < http://www.anped.org.br/sites/default/files/t1111.pdf> acesso em 03 de jun 2020.

FREIRE, S. Um olhar sobre a inclusão. In: Revista da Educação, Vol. XVI, n.01, p. 05-20, 2008. Disponível em:<

https://repositorio.ul.pt/bitstream/10451/5299/1/Um\%20olhar\%20sobre\%20a\%20Inclus\%C3\%A3o.p df >acesso em 04 jun 2020.

GOMES, Mônica Araújo; PEREIRA, Maria Lúcia Duarte. Família em situação de vulnerabilidade social: uma questão de políticas pública. Ciência Saúde Coletiva v.10 n.2 Rio de Janeiro abr./jun. 2005. Disponível em:< https://www.scielo.br/pdf/csc/v10n2/a13v10n2.pdf . Acesso em 02 jun 2020.

HOWKINS, John. Economia Criativa: como ganhar dinheiro com ideias criativas. São Paulo: M.Books, 2012.

INSTITUTO BRASILEIRO DE GEOGRAFIA E ESTATÍSTICA (IBGE). Censo Demográfico 2010. Famílias e domicílios. Resultados da amostra. Rio de Janeiro, 1-203, 2012.

MANZINI, Ezio. Making Things Happen: Social Innovation and Design. Design Issues, v.30 n.1, 2014.

MULGAN, Geoff et al. Social innovation: what it is, why it matters and how it can be accelerated. 2007. Disponível em<

file:///C:/Users/usuario/Downloads/Social_Innovation_What_It_Is_Why_It_Matters_and_Ho.pdf> Acesso em 2 jun 2020

SANTOS, Heliana Marcia. Redesign do calçado com solado de corda a partir dos resíduos têxteis da indústria do vestuário: inovação de material e avaliação de conforto. 2015. 100 f. Dissertação (mestrado) - Universidade Estadual Paulista Julio de Mesquita Filho, Faculdade de Arquitetura, Artes e Comunicação, 2015. Disponível em: <http://hdl.handle.net/11449/136696>. 